\title{
Caracterização Físico-Mecânica da Madeira Jovem de Eucalyptus camaldulensis para Aplicação na Arquitetura Rural
}

\author{
Pablo Marcel de Arruda Torres ${ }^{1}$, Juarez Benigno Paes², \\ José Wallace Barbosa do Nascimento ${ }^{3}$, Flávia Maria Silva Brito ${ }^{2}$
}

${ }^{1}$ Unidade Acadêmica de Desenho Industrial, Universidade Federal de Campina Grande - UFCG, Campina Grande/PB, Brasil ${ }^{2}$ Departamento de Ciências Florestais e da Madeira, Universidade Federal do Espírito Santo - UFES, Jerônimo Monteiro/ES, Brasil

${ }^{3}$ Unidade Acadêmica de Engenharia Agrícola, Universidade Federal de Campina Grande - UFCG, Campina Grande/PB, Brasil

\begin{abstract}
RESUMO
O objetivo deste trabalho foi analisar a qualidade da madeira de árvores jovem de Eucalyptus camaldulensis plantada em Rio Tinto, Paraíba, para sua utilização na arquitetura rural. Foram realizados ensaios físico-mecânicos, por meio da caracterização simplificada da madeira. Nos ensaios físicos foram obtidos o teor de umidade, massa específica básica e aparente e retratibilidade da madeira, além do coeficiente de anisotropia; e no ensaio mecânico para a tomada da compressão paralela às fibras foram utilizados transdutores de deslocamento linear (LVDTs) acoplados à amostra e ao sistema de aquisição de dados para a determinação dos valores de resistência e rigidez da madeira. Os valores obtidos demonstraram que a madeira jovem de E. camaldulensis se enquadra na classificação de resistência C 20 para madeiras de folhosas, determinada pela Norma Brasileira, não sendo recomendada para fins estruturais, porém pode ser aplicada em elementos secundários de arquitetura rural, como cercas, parques e mobiliário rural.
\end{abstract}

Palavras-chave: caracterização simplificada, propriedades da madeira, mobiliário rural.

\section{Physical and Mechanical Characterization of Eucalyptus camaldulensis Young Wood for Rural Architecture Uses}

\begin{abstract}
This study aimed to analyze the quality of Eucalyptus camaldulensis young wood of planted trees in Rio Tinto, Paraíba, Brazil, for use in rural architecture. Physico-mechanical tests were carried out through simplified characterization. The physical tests obtained were moisture content, basic and apparent specific gravity and shrinkage of the wood, in addition to the anisotropy coefficient. To obtain the compression parallel to fibers results, linear variable differential transformers (LVDTs) bound to the sample and the data acquisition system for the determination of the resistance and stiffness values of wood were used. The values obtained showed that the young wood of E. camaldulensis fits in $20 \mathrm{C}$ strength rating for hardwoods, determined by the Brazilian Standard, still not being recommended for structural purposes, but appropriate to be applied in secondary elements of rural architecture, as fences, playgrounds and for rustic furniture manufacture.
\end{abstract}

Keywords: simplified wood characterization, wood properties, rural furniture. 


\section{INTRODUÇÃO}

Por se tratar de um gênero com espécies que se adaptam a diferentes condições climáticas, o eucalipto é plantado praticamente em todas as regiões do Brasil, sendo a árvore mais utilizada em reflorestamentos no País, seguida do Pinus, plantado basicamente na Região Sul (Terezo, 2001).

O eucalipto conquistou posição significativa na indústria de celulose e papel e na produção de carvão vegetal, razão pela qual vem recebendo cada vez mais tratamento científico, conquistando ganho em qualidade e produtividade por meio de técnicas de melhoramento genético, tratos silviculturais e manejo florestal. A busca pelo uso múltiplo das florestas e de melhor remuneração para a madeira tem incentivado o estabelecimento de estratégias por parte das empresas, com vistas à oferta de madeira serrada de eucalipto (Flynn \& Shield, 1999).

Uma vez que o reflorestamento de eucalipto no Brasil foi introduzido com propósitos energéticos, não havia preocupação com a produção de madeira serrada. Este aspecto refletiu no fornecimento ao mercado de toras de qualidade inferior para produção de produtos sólidos, originando o mito de que a madeira de eucalipto não serve para utilização em construções ou mobiliário. De fato, a madeira de eucalipto apresenta uma série de problemas naturais que podem ser minimizados com práticas adequadas de desdobro e secagem (Bacha \& Barros, 2004).

De acordo com Watai (1990), um dos maiores problemas na utilização do eucalipto como madeira serrada são as tensões de crescimento e de secagem, que causam perdas de até $50 \%$ da madeira serrada, além de provocar rachaduras e empenamentos. Operações corretas de desdobro diminuem os defeitos na madeira, enquanto a presença de nós é outra característica negativa, passível de ser minimizada por meio da desrama adequada do povoamento.

De modo geral, para a utilização do eucalipto como madeira serrada de qualidade são necessárias melhorias na adaptação da tecnologia de produção (melhoramento genético e práticas silviculturais adequadas, como desbaste e desrama), na tecnologia de processamento (técnicas adequadas de abate, desdobro e secagem), até a fase de utilização (acabamento e design), comercialização e aproveitamento de seus subprodutos (Flynn \& Shield, 1999).

Apesar dos problemas tecnológicos referentes ao eucalipto, a produção de madeira serrada no Brasil e no mundo, tem demonstrado elevada taxa de crescimento nos últimos anos. As restrições de corte das matas nativas, associadas ao crescimento da demanda, estão levando à utilização das florestas cultivadas, especialmente as de rápido crescimento. Neste contexto, a madeira de eucalipto tende a assumir papel de destaque em termos de mercado (Bacha \& Barros, 2004). Segundo dados da Indústria Brasileira de Árvores - IBÁ (2015) a produção de madeira de eucalipto para a indústria madeireira (produtos sólidos) foi de 7,03 milhões de $\mathrm{m}^{3}$ em 2014.

O Eucalyptus camaldulensis é uma espécie nativa da Austrália, geralmente encontrada ao longo dos cursos dos rios, quer sejam permanentes ou sazonais. A espécie foi identificada com esse nome em homenagem ao mosteiro Camaldoli, próximo de Nápoles (Itália), onde o primeiro exemplar foi descrito (Brooker et al., 2002).

Segundo o "Commonwealth Scientific and Industrial Research Organisation" - CSIRO (2004), a madeira do E. camaldulensis é brilhante e avermelhada, podendo variar desde o rosa até o vermelho escuro, quase preto, dependendo da idade e umidade; é resistente à podridão e geralmente usada em aplicações como tacos, dormentes, cruzetas e, mais recentemente, foi reconhecida como material para confecção de mobiliário artesanal em virtude da cor vermelha e textura típica. Porém ela precisa de seleção cuidadosa uma vez que tende a ser bastante reativa às mudanças de umidade. É muito dura, densa (cerca de $900 \mathrm{~kg} \mathrm{~m}^{-3}$ ), podendo apresentar facilidade de ser cortada e torneada, além de poder receber polimento fino.

Em função de suas características físico-mecânicas, a madeira de E. camaldulensis tem sido utilizada para construção pesada, dormentes ferroviários, pisos, vigamento, cercas, madeira torneada, na produção de lenha e carvão e na fabricação de compensado (Boland et al., 2006).

A arquitetura rural ainda é uma especialidade pouco explorada e pesquisada, constituindo um abrangente campo de estudos e atuação. Engloba o estudo da habitação rural, das construções rurais para produção, armazenamento agrícola e para a proteção de máquinas e equipamentos, do patrimônio cultural 
rural, além do planejamento e gestão da produção e serviços agrícolas (Ferrão, 2006).

Produtos madeireiros são empregados com frequência na arquitetura rural, na solução de problemas relacionados à cobertura, travessia de obstáculos (pontes, viadutos e passarelas para pedestres), armazenamento (silos verticais e horizontais), linhas de transmissão (energia elétrica e telefonia) e benfeitorias rurais (Calil \& Dias, 1997)

Em função da importância da madeira de Eucalyptus para os mais diversos usos, este trabalho teve como objetivo analisar a qualidade da madeira jovem de Eucalyptus camaldulensis Dehnh. plantada em Rio Tinto, PB, por meio das características físico-mecânicas, para sua aplicação na arquitetura rural (cercas, galpões, quiosques e móveis rústicos).

\section{MATERIAL E MÉTODOS}

\subsection{Procedência, seleção e coleta das árvores}

As árvores de Eucalyptus camaldulensis Dehnh. foram coletadas na propriedade da Cerâmica Cincera, localizada na Zona Rural do Município de Rio Tinto, Paraíba (latitude $6^{\circ} 48^{\prime} 27^{\prime \prime}$ S e longitude $35^{\circ} 04^{\prime} 05^{\prime \prime} \mathrm{W}$ ). No povoamento, foram escolhidas, aleatoriamente, cinco árvores, sendo três com diâmetro médio de $21,50 \mathrm{~cm}$ e duas com diâmetro de $17,00 \mathrm{~cm}$, medidos a 1,30 m do nível do solo. As árvores eram jovens, com cerca de quatro anos de idade (plantadas em julho de 2003 e colhidas em novembro de 2007) e tinham, em média, 20 metros de altura total.

As árvores foram cortadas com motosserra e, após o corte, os troncos foram subdivididos em toras de quatro metros de comprimento, cada árvore deu origem a quatro toras. Ao seccionar os troncos, retiraram se discos de $\pm 2,5 \mathrm{~cm}$ de espessura, nas posições correspondentes à base e ao topo de cada tora, que foram identificados e armazenados em sacos plásticos e destinados à determinação da densidade básica da árvore, conforme o indicado por Vital (1984).

As toras foram transportadas para o Campus da Universidade Federal de Campina Grande - UFCG, em Patos, $\mathrm{PB}$ (latitude $7^{\circ} 01^{\prime} 31^{\prime}$ 'S e longitude $37^{\circ} 16^{\prime} 40^{\prime \prime} \mathrm{W}$ ), onde foram descascadas com o uso de ferramentas manuais. As toras mais finas (diâmetro de 9 a $12 \mathrm{~cm}$ ), provenientes da quarta ou terceira secção do tronco, foram destinadas a tratamento pelo método de substituição da seiva por transpiração radial (Torres et al., 2011), e aquelas mais grossas, provenientes principalmente da primeira ou segunda seção (diâmetro de 15 a 21,50 cm), foram destinadas à confecção dos corpos de prova para os ensaios físico-mecânicos, seguindo as especificações da Norma Brasileira Regulamentadora - NBR 7190 da Associação Brasileira de Normas Técnica (ABNT, 1997).

\subsection{Seleção das toras e confecção dos corpos de prova}

As toras mais grossas foram submetidas à secagem ao ar livre em local coberto e ventilado até atingirem 25 a 30\% de umidade, e após o período de secagem (60 dias), aquelas de melhor qualidade, as quais tiveram menores rachaduras, foram desdobradas. Antes do desdobro primário, as peças foram seccionadas, tendo seu comprimento padronizado em 2,0 metros. O seccionamento e o esquadrejamento das toras (retirada das costaneiras) foram realizados em uma serraria, em Patos, PB.

A confecção dos corpos de prova foi realizada no Laboratório de Tecnologia de Produtos Florestais LTPF, UFCG, em Patos, PB. Para a determinação das propriedades físicas da madeira (teor de umidade, massa especifica aparente e retratibilidade), confeccionaram-se corpos de prova com dimensões de $2 \times 3 \times 5 \mathrm{~cm}$ (tangencial $\mathrm{x}$ radial $\mathrm{x}$ longitudinal) e para o ensaio mecânico (compressão paralela às fibras), foram utilizados amostras com dimensões de 5 × 5 x $15 \mathrm{~cm}$ (tangencial $\mathrm{x}$ radial $\mathrm{x}$ longitudinal).

\subsection{Propriedades físico mecânicas da madeira}

As propriedades físico mecânicas da madeira foram determinadas de acordo com as especificações da NBR 7190 (ABNT, 1997) para a caracterização simplificada da madeira. Os ensaios de propriedades físicas da madeira foram realizados no LTPF, e os de compressão paralela às fibras no Laboratório de Solos I, localizado no Campus de Campina Grande, PB.

Para a determinação da massa específica aparente da madeira, os corpos de prova foram postos em ambiente climatizado $\left(25 \pm 2^{\circ} \mathrm{C}\right.$ e $65 \pm 5 \%$ de umidade $)$ até atingirem massa constante e umidade de equilíbrio aproximada de $12 \%$. As dimensões das amostras foram tomadas com paquímetro digital $(0,01 \mathrm{~mm}$ de precisão) 
e a massa em balança digital com precisão de $0,01 \mathrm{~g}$, tendo a massa especifica aparente sido obtida ao dividir a massa pelo volume da madeira.

Para a determinação da densidade básica o volume saturado da madeira foi determinado após a imersão das amostras (duas cunhas diametralmente opostas) em água, até que atingissem massa constante ou com no máximo $0,5 \%$ de variação em relação à massa anterior.

$\mathrm{Na}$ obtenção da massa seca os corpos de prova e amostras (cunhas) foram postos em estufa com temperatura de $103 \pm 2{ }^{\circ} \mathrm{C}$, até massa constante. Durante o processo de secagem a massa dos corpos de prova e amostras foi medida a cada 6 horas até que ocorresse uma variação entre duas medidas consecutivas, menor ou igual a $0,5 \%$ em relação à última massa medida definindo, assim, a massa seca. A massa específica básica foi determinada ao dividir a massa seca da amostra pelo volume saturado.

Com os valores da massa inicial e a massa seca das amostras calculou-se o teor de umidade, em base seca. De posse das dimensões saturada e seca dos corpos de prova determinaram-se a retração e o inchamento da madeira (axial, radial, tangencial e volumétrico), conforme especificações da NBR 7190 da ABNT (1997).

$\mathrm{O}$ ensaio de compressão paralela às fibras foi realizado de acordo com a NBR 7190 (ABNT, 1997) e os procedimentos descritos por Rocha et al. (2015). Assim, as dimensões dos corpos de prova foram tomadas com um paquímetro digital de precisão $0,01 \mathrm{~mm}$; e realizou-se um ensaio destrutivo com um dos corpos de prova do lote, a partir de um carregamento crescente, à taxa de $10 \mathrm{MPa} \min ^{-1}$, visando estimar o valor da resistência da madeira. A seguir, quatro cantoneiras metálicas foram fixadas com parafuso nos corpos de prova a serem testados, a uma distância nominal de $10 \mathrm{~cm}$ entre as cantoneiras na linha de fixação (Figura 1) e dois transdutores de deslocamento linear (LVDTs) foram fixados às cantoneiras a fim de se medir o deslocamento provocado pela compressão sobre a madeira.

Os corpos de prova foram ajustados entre os pratos de uma máquina universal de ensaio, com capacidade máxima de 60 toneladas, sobre uma rótula e entre um espaçador metálico. Constatou-se a necessidade da utilização de um espaçador de aço maciço, em função da fiação proeminente dos LVDTs, que impediam o

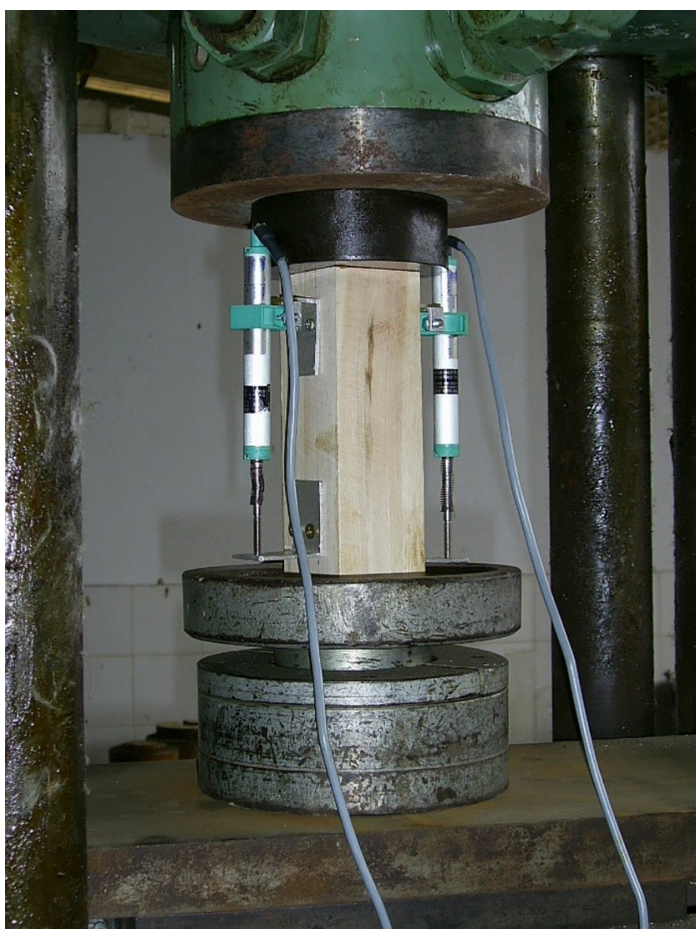

Figura 1. LVDTs nos lados do corpo de prova e detalhes do espaçador e da rótula.

Figure 1. LVDTs on the sides of test sample and details of spacer and kneecap.

corpo de prova de ser posicionado na prensa (Figura 1), conforme descrito por Rocha et al. (2015).

Os LVDTs foram conectados ao sistema de aquisição de dados e ao computador que continha o software de controle. O sistema de coleta de dados foi acionado no "datalogger" com amostragem de recebimento de duas leituras por segundo. Realizou-se o carregamento de forma monotônica crescente a uma taxa de $10 \mathrm{MPa} \mathrm{min}^{-1}$ com dois ciclos de carga e descarga. Os primeiro e segundo ciclos compreenderam o carregamento do corpo de prova até $50 \%$ da resistência em que a carga foi mantida durante 30 segundos; decorrido este tempo houve uma descarga para $10 \%$, mantida durante mais 30 segundos. Este procedimento está em acordo com a NBR 7190 (ABNT, 1997) para que as fibras da madeira sejam acomodadas.

No carregamento final, as leituras foram realizadas a cada $10 \%$ de carregamento, até atingir $70 \%$ da carga estimada. Ao constatar que a carga havia atingido esta porcentagem de carregamento, retiraram-se os LVDTs do corpo de prova. Após a retirada dos LVDTs elevou-se o carregamento até a ruptura da amostra (Figura 2). 


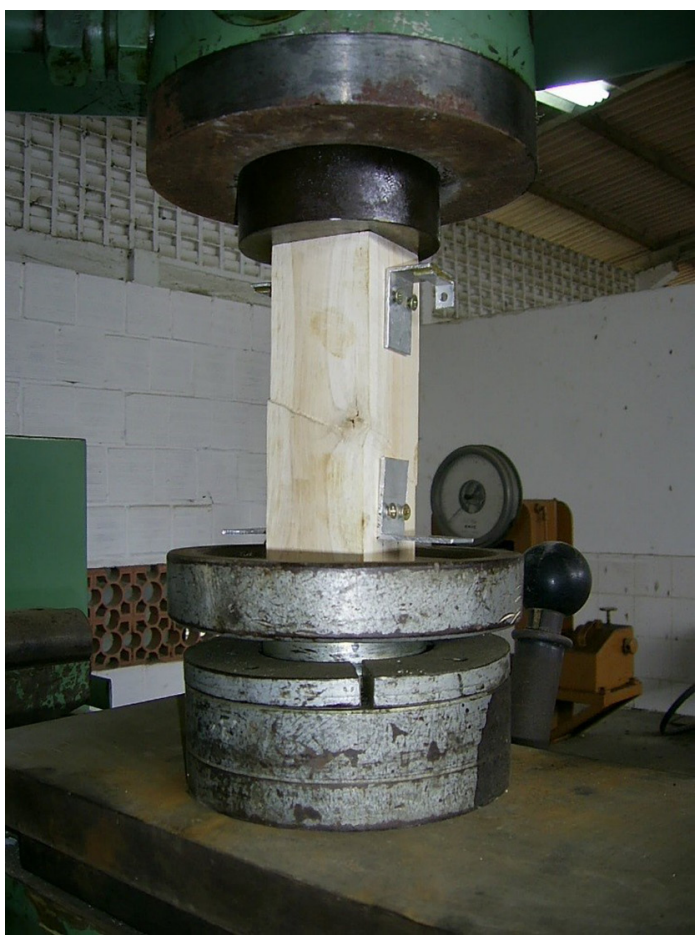

Figura 2. Corpo de prova após a ruptura.

Figure 2. Test sample after the rupture.

O observador registrava o tempo, em segundos, decorrido do início do ensaio, em que o operador da prensa informava a passagem pelos pontos de carga e descarga com base nos valores da resistência máxima estimada. Os intervalos de 30 segundos entre cada carga e descarga foram controlados pelo operador da prensa, orientado por um cronômetro digital; em seguida processou-se o cruzamento dos dados coletados pelo "datalogger" com as marcações de tempo, registrados anteriormente pelo observador, a fim de realizar a leitura nos pontos predefinidos.

Obteve-se a resistência a compressão paralela às fibras da madeira pela máxima tensão de compressão que pode atuar em um corpo de prova, calculada segundo a NBR 7190 (ABNT, 1997). Os valores obtidos das resistências foram corrigidos para umidade padrão de referência de 12\%, de acordo com a NBR 7190 (ABNT, 1997). Os resultados obtidos foram dispostos em ordem crescente, não se tomando para resistência à compressão valor inferior ao menor valor nem a 0,7 do valor médio.

A rigidez da madeira na direção paralela às fibras foi determinada por seu módulo de elasticidade obtido a partir da inclinação da reta secante à curva tensão $\mathrm{x}$ deformação específica, definida pelos pontos correspondentes a $10 \%$ e $50 \%$ da resistência a compressão paralela às fibras, medida no ensaio, conforme NBR 7190 (ABNT, 1997). Os valores da rigidez obtidos foram corrigidos para umidade padrão, de acordo com a NBR 7190 (ABNT, 1997).

\subsection{Aplicação da madeira na confecção de um móvel para o meio rural}

As toras provenientes da quarta ou terceira secção do tronco foram submetidas a tratamento preventivo (Torres et al., 2011) e utilizada para confecção do protótipo de um mobiliário em escala real que pudesse exemplificar sua aplicação em elementos de arquitetura rural.

Como as toras de eucalipto têm diâmetro reduzido, sobretudo se levando em consideração que ainda passariam por processos de desdobro, as peças resultantes possuíam pequena largura, o que limitava as possibilidades de confecção do móvel.

Partindo-se dessas observações, o modelo de mobiliário escolhido para ser confeccionado foi de uma pequena mesa de apoio cujo tampo seria quadrado e confeccionado com os sarrafos mais finos da madeira, dispostos lado a lado; as toras de maior diâmetro foram selecionadas para a confecção dos pés e das travessas de sustentação do móvel.

Com relação ao desdobro da madeira, primeiro as toras foram esquadrejadas em uma plaina, que desbastou a madeira e aplainou suas superfícies e as dimensões das mesmas foram ajustadas em uma serra circular esquadrejadeira, segundo dimensionamento previamente definido. As superfícies das peças foram passadas em uma lixadeira de cinta e fixadas entre si por meio de encaixes, cola e pregos.

\subsection{Análise dos resultados}

Para as propriedades físicas da madeira (massa específica básica e aparente, umidade e retratibilidade), realizaram-se cálculos estatísticos simples, em que os valores de média, desvio-padrão e coeficiente de variação, foram empregados.

Com relação às propriedades mecânicas da madeira determinadas pelo ensaio de compressão paralela às fibras, para análise os dados de resistência e rigidez, empregou-se o valor característico à compressão paralela 
às fibras, calculado a $12 \%$ de umidade, conforme estipulado pela NBR 7190 (ABNT, 1997).

Na confecção do móvel (mesa) foram observadas as características relacionadas à usinagem da madeira, aos encaixes e fixações. Não se empregou nenhum tipo de acabamento, uma vez que a mesa foi confeccionada com madeira tratada.

\section{RESULTADOS E DISCUSSÃO}

\subsection{Propriedades físicas da madeira}

A madeira jovem de E. camaldulensis obteve massa específica aparente de $0,581 \mathrm{~g} \mathrm{~cm}^{-3}\left(581 \mathrm{~kg} \mathrm{~m}^{-3}\right)$, com coeficiente de variação de $6,07 \%$ (Tabela 1 ). Este valor foi menor que o apresentado pela NBR 7190 (ABNT, 1997), que foi de $899 \mathrm{~kg} \mathrm{~m}^{-3}$ para a madeira adulta de E. camaldulensis, o que pode ter ocorrido em razão da madeira ser jovem, com cerne pouco desenvolvido. Já a massa específica básica foi de $0,470 \mathrm{~g} \mathrm{~cm}^{-3}\left(470 \mathrm{~kg} \mathrm{~m}^{-3}\right)$, com coeficiente de variação de 6,27\%.

O teor de umidade médio para a madeira ao ser ensaiada foi de 10,82\%, com coeficiente de variação de $15,13 \%$, portanto, superior ao da umidade de referência de 12\%, referenciado pela NBR 7190 (ABNT, 1997), necessitando, neste caso, conforme a norma citada, de correção nos valores de resistência e rigidez da madeira.

Os resultados da estabilidade dimensional da madeira (contração e inchamento e coeficientes de anisotropia) encontram-se na Tabela 2 . A deformação média de contração na direção radial foi de $4,70 \%$, com coeficiente de variação de $21,98 \%$; na tangencial, de $6,91 \%$, com coeficiente de variação de $4,80 \%$ e, na longitudinal, de $0,77 \%$, com coeficiente de variação de $108,29 \%$ e a variação volumétrica média foi de $12,38 \%$, com coeficiente de variação de 30,05\%. Já a deformação média de inchamento na direção radial foi de 4,94\%, e o coeficiente de variação de 23,10\%; na tangencial, de 7,55\%, com coeficiente de variação de 53,35\% e, na longitudinal, de $0,78 \%$, cujo coeficiente de variação foi de $109,26 \%$, e a variação volumétrica média foi de $13,76 \%$, com coeficiente de variação de 35,05\%.

Para a contração na madeira jovem de Eucalyptus camaldulensis foram obtidos baixos valores quando comparados a espécies de Eucalyptus empregadas para uso múltiplo, como o Eucalyptus saligna, com 16 anos (Oliveira \& Silva, 2003), que foi de 7,67\% (radial), 14,83\% (tangencial) e 26,00\% (volumétrica) e a madeira de sete espécies de Eucalyptus, com idade de 16 anos, pesquisadas por Oliveira et al. (2010),

Tabela 1. Densidade aparente, densidade básica e umidade da madeira jovem de E. camaldulensis.

Table 1. Apparent and basic specific gravities and moisture content of E. camaldulensis young wood.

\begin{tabular}{lccc}
\multicolumn{1}{c}{ E. camaldulensis } & $\begin{array}{c}\text { Densidade Aparente } \\
\left(\mathbf{g ~ c m}^{-3}\right)\end{array}$ & $\begin{array}{c}\text { Densidade Básica } \\
\left(\mathbf{g ~ c m}^{-3}\right)\end{array}$ & Teor de Umidade (\%) \\
Média & 0,581 & 0,470 & 10,82 \\
Desvio padrão & 0,035 & 0,029 & 1,637 \\
Coeficiente de Variação (\%) & 6,070 & 6,270 & 15,130 \\
\hline
\end{tabular}

Tabela 2. Deformações específicas de contração e inchamento.

Table 2. Specific deformation of shrinkage and swelling.

\begin{tabular}{|c|c|c|c|c|c|}
\hline \multirow[b]{2}{*}{ E. camaldulensis } & \multicolumn{5}{|c|}{ Deformação de Contração } \\
\hline & Radial & Tangencial & Longitudinal & Volumétrica & $\begin{array}{l}\text { Coeficiente } \\
\text { Anisotropia }\end{array}$ \\
\hline Média & 4,70 & 6,91 & 0,77 & 12,38 & 1,55 \\
\hline Desvio Padrão & 1,03 & 3,23 & 0,84 & 3,75 & 0,96 \\
\hline $\mathrm{CV}(\%)$ & 21,98 & 46,80 & 108,29 & 30,05 & 61,86 \\
\hline \multirow[b]{2}{*}{ E. camaldulensis } & \multicolumn{5}{|c|}{ Deformação de Inchamento } \\
\hline & Radial & Tangencial & Longitudinal & Volumétrica & $\begin{array}{l}\text { Coeficiente } \\
\text { Anisotropia }\end{array}$ \\
\hline Média & 4,94 & 7,55 & 0,78 & 13,76 & 1,63 \\
\hline Desvio Padrão & 1,14 & 4,03 & 0,85 & 4,82 & 1,16 \\
\hline CV (\%) & 23,10 & 53,35 & 109,26 & 35,05 & 71,39 \\
\hline
\end{tabular}


que variaram de 5,0\% (Eucalyptus grandis) a 9,4\% (Eucalyptus paniculata), na direção radial; de 9,3\% (Eucalyptus cloeziana) a 15,5\% (Eucalyptus paniculata), na direção tangencial; e de 15,9\% (Eucalyptus grandis) para 27,2\% (Eucalyptus paniculata). A dos Eucalyptus saligna e Eucalyptus dunii, com 11 anos, estudadas por Batista et al. (2010), que variaram de 5,03\% e 5,70\% (radial); de 9,86\% e 12,74\% (tangencial); e $15,61 \%$ e $18,71 \%$ (volumétrica), respectivamente.

Em função da pequena variação nas dimensões longitudinais dos corpos de prova, tanto na retração quanto no inchamento, tais medidas estão sujeitas a erros operacionais o que, provavelmente, tenha sido o responsável pelo alto coeficiente de variação apresentado nas deformações de retração e de inchamento longitudinais.

As deformações de inchamento foram maiores que as de contração em todas as direções (longitudinal, radial, tangencial e volumétrica), em função do efeito da histerese (Skarr, 1988; Siau, 1995).

Quanto ao coeficiente de anisotropia (razão entre a contração tangencial e a radial), Scavanaca \& Garcia (2004) afirmaram que, quanto mais próximo de 1 melhor é a madeira para marcenaria. O E. camaldulensis apresentou coeficiente de anisotropia de 1,55 para retração, com coeficiente de variação de $61,86 \%$, e de 1,63 para inchamento, com coeficiente de variação de $71,39 \%$. Os valores de coeficiente de anisotropia obtidos foram inferiores aos encontrados por Oliveira \& Silva (2003), Batista et al. (2010) e Oliveira et al. (2010), ao estudarem a madeira de outras espécies de eucalipto.

Os valores indicam que a madeira possui restrições quanto à sua aplicação em marcenaria; contribuem, para este resultado, o fato da madeira pesquisada ser muito jovem e seu lenho ainda estar em desenvolvimento, o que eleva a ocorrência de tensões de crescimento e, como consequência, e o desenvolvimento de rachaduras de secagem e de tensão de crescimento nas peças.

\subsection{Propriedades mecânicas da madeira}

O valor característico da resistência à compressão paralela às fibras do lenho jovem do Eucalyptus camaldulensis, obtido e o corrigido para a umidade de $12 \%$ de umidade, contam da Tabela 3 . O valor característico corrigido para a resistência foi de 25,31 MPa; já para a rigidez foi de 12,379 MPa; logo, a madeira pode ser enquadrada na classe C 20 de
Tabela 3. Resistência e rigidez obtidas e corrigidas para umidade padrão de $12 \%$ para a madeira jovem de E. camaldulensis.

Table 3. Strength and rigidity obtained and corrected to standard moisture $12 \%$ to the E. camaldulensis young wood.

\begin{tabular}{cccc}
$\begin{array}{c}\text { Resistência } \\
\text { Obtida }\end{array}$ & $\begin{array}{c}\text { Resistência } \\
\text { a 12\% }\end{array}$ & $\begin{array}{c}\text { Rigidez } \\
\text { Obtida }\end{array}$ & $\begin{array}{c}\text { Rigidez a } \\
\mathbf{1 2 \%}\end{array}$ \\
$23,39 \mathrm{MPa}$ & $25,31 \mathrm{MPa}$ & $11.699 \mathrm{MPa}$ & $12.379 \mathrm{MPa}$ \\
\hline
\end{tabular}

referência para folhosas (dicotiledôneas), conforme a NBR 7190 da ABNT (1997).

A massa específica a aparente do lenho juvenil do Eucalyptus camaldulensis (581 $\mathrm{kg} \mathrm{m}^{-3}$ ) foi próxima à do pinheiro do Paraná (Araucaria angustifolia), com valor de $580 \mathrm{~kg} \mathrm{~m}^{-3} \mathrm{e}$ um pouco maior que a do Pinus elliottii $\left(560 \mathrm{~kg} \mathrm{~m}^{-3}\right)$, madeira muito comum em reflorestamentos na Região Sul do Brasil, estando também próxima a do Eucalyptus grandis $\left(640 \mathrm{~kg} \mathrm{~m}^{-3}\right)$, embora inferior à do Eucalyptus paniculata $\left(1.087 \mathrm{~kg} \mathrm{~m}^{-3}\right)$ e da madeira madura do Eucalyptus camaldulensis $\left(899 \mathrm{~kg} \mathrm{~m}^{-3}\right)$, conforme valores apresentados na NBR 7190 (ABNT, 1997).

Quanto à rigidez (MOE), o valor obtido (12.379 MPa) se aproximou daqueles do Eucalyptus grandis (12.813 MPa) e Pinus elliottii (11.889), sendo menor que os valores apresentados para o Eucalyptus camaldulensis adulto (13.286 MPa) e, sobretudo, para o Eucalyptus paniculata (19.881 MPa).

Os valores de resistência (MOR) e da Rigidez (MOE) a compressão paralela às fibras da madeira de eucalipto estudada foi inferior às demais madeiras de eucalipto, citadas pela NBR 7190 (ABNT, 1997), em razão do lenho jovem ser menos resistente que o da madeira adulta.

\subsection{Confecção de um móvel para uso no meio rural}

O móvel para o meio rural confeccionado com a madeira tratada de E. camaldulensis é apresentado na Figura 3. As peças prismáticas mais grossas, com dimensões de $6,0 \times 6,0 \mathrm{~cm}$, provenientes das toras com diâmetro de 11,0 a 12,0 cm tratadas (Torres et al., 2011), foram utilizadas como pernas da mesa de apoio; as demais, provenientes das peças mais finas $(9,0$ a $11,0 \mathrm{~cm})$ foram usinadas e resultaram em oito sarrafos com 1,0 x 10,0 x 80,0 cm (espessura x largura $\mathrm{x}$ 


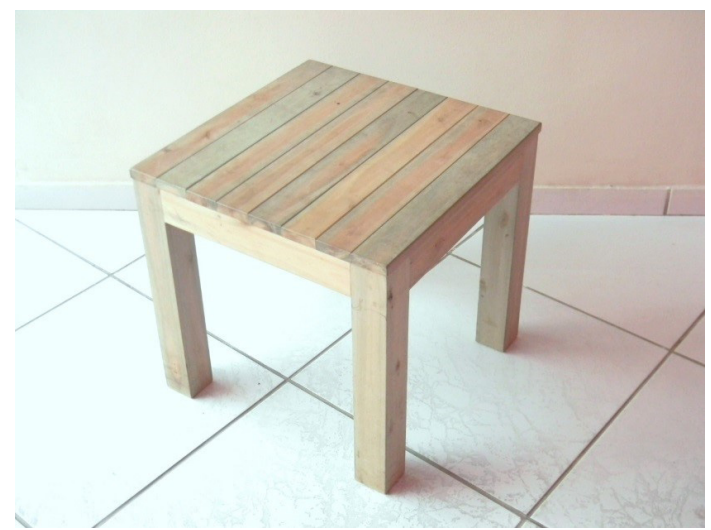

Figura 3. Mesa confeccionada com madeira tratada de E. camaldulensis.

Figure 3. Table manufactured with treated wood of E. camaldulensis.

comprimento) os quais foram utilizados como cobertura para o tampo e a outros quatro de $3,0 \times 10,0 \times 68,0 \mathrm{~cm}$ (espessura $\mathrm{x}$ largura $\mathrm{x}$ comprimento) que foram utilizados como travessas horizontais, que unem as pernas da mesa. A mesa produzida teve altura de $80,0 \mathrm{~cm}$ e dimensões laterais de 80,0 x 80,0 cm.

O móvel não recebeu qualquer tipo de acabamento adicional, o que tornou a apresentação da madeira fiel às suas características principais; a coloração variou entre um tom rosa claro e o verde, em função da presença do cerne e da substância preservativa no alburno.

Como a madeira de Eucalyptus camaldulensis utilizada na pesquisa foi plantada para a produção de energia, em que não se teve a preocupação com a desrama (poda), verificou-se a presença constante de nós na madeira, o que prejudica esteticamente sua aplicação como mobiliário. Assim, para produção visando à aplicação em arquitetura rural, o que exige maior qualidade da madeira, é necessário que se executem práticas silviculturais, como o desbaste e a desrama em períodos específicos do crescimento da árvore, além da secagem correta da madeira. Esses cuidados minimizam a quantidade de nós, além de evitar empenamentos e rachaduras excessivas, que comprometem a qualidade do produto final.

\section{CONCLUSÕES}

Com os dados obtidos nos ensaios físico-mecânicos, foi possível realizar a caracterização simplificada da madeira juvenil do Eucalyptus camaldulensis Dehnh. e enquadrá-la na classe C 20 , sendo esta a classe de menor resistência, como determinada pela Norma Brasileira. Dados de resistência, rigidez e massa específica da madeira estudada, são comparáveis aos de algumas espécies de coníferas cultivadas no Brasil.

A madeira jovem do Eucalyptus camaldulensis apresenta baixa resistência e rigidez quando comparada a várias espécies de Eucalyptus, não sendo recomendada sua utilização para fins estruturais; no entanto, pode ser utilizada em casos que não exijam grandes esforços, como em cercas, portões, mobília e paisagismo rurais.

Como a madeira de Eucalyptus camaldulensis utilizada no experimento era jovem (lenho juvenil), apresentou alguns problemas em seu desdobro e secagem ao ar, como empenamento e rachaduras excessivas, em função das tensões de crescimento. Como não se trata de uma madeira proveniente de árvores plantada com a finalidade específica de se fabricar móveis, o que exige maior qualidade, a mesma apresentou nós em diversos pontos, ao longo do seu comprimento, problema passível de ser resolvido com o desbaste e desrama das árvores em períodos específicos de seu crescimento.

\section{STATUS DA SUBMISSÃO}

Recebido: 14 set.,2012

Aceito: 24 jul., 2015

\section{AUTOR(ES) PARA CORRESPONDÊNCIA}

\section{Juarez Benigno Paes}

Departamento de Ciências Florestais e da Madeira, Universidade Federal do Espírito Santo - UFES, Av. Governador Lindember, 316, Centro, CEP 29550-000, Jerônimo Monteiro, ES, Brasil e-mail: jbp2@uol.com.br

\section{REFERÊNCIAS}

Associação Brasileira de Normas Técnicas - ABNT. NBR 7190: projeto de estruturas de madeira. Anexo B Determinação das propriedades das madeiras para projeto de estruturas. Rio de Janeiro: ABNT; 1997. 107 p.

Bacha CJC; Barros ALM. Reflorestamento no Brasil: evolução recente e perspectivas para o futuro. Scientia Forestalis 2004; (66): 191-203.

Batista DC, Klitzke JR, Santos CVT. Densidade básica e retratibilidade da madeira de clones de três espécies de 
Eucalyptus. Ciência Florestal 2010; 20(4): 665-674. http:// dx.doi.org/10.5902/198050982425.

Boland DJ, Brooker MIH, Chippendale GM, Hall N, Hyland BPM, Johnston RD, et al. Forest trees of Australia. 5. ed. Melbourne: CSIRO Publishing; 2006. 768 p.

Brooker MIH, Connors JR, Slee AV, Duffy SE. Eucalypts of southern Australia. Collingwood: CSIRO Publishing; 2002. CD-ROM.

Calil C Jr, Dias AA. Utilização da madeira em construções rurais. Revista Brasileira de Engenharia Agrícola e Ambiental 1997; 1(1): 71-77.

Commonwealth Scientific and Industrial Research Organisation - CSIRO. Eucalyptus camaldulensis Dehnh: River Red Gum [online]. Armidale: CSIRO; 2004. [citado em 2007 out 25]. Disponível em: http://www.anbg.gov. $\mathrm{au} / \mathrm{cpbr} / \mathrm{WfHC} /$ Eucalyptus-camaldulensis

Ferrão AMA. Arquitetura rural. In: Anais do III Congresso Brasileiro de Assistência Técnica e Extensão Rural [CDROM]; 2006; Campinas. Campinas: Fundação de Estudos Agrários Luiz de Queiroz; 2006.

Flynn B, Shield E. Eucalyptus progress in higher value utilization: a global review. Tacoma: Robert Flynn \& Associates; $1999.212 \mathrm{p}$.

Indústria Brasileira de Árvores - IBÁ. Relatório Ibá 2015 [online]. Brasília: IBÁ; 2015. 80 p. [citado em 2015 dez. 13]. Disponível em: http://iba.org/images/shared/ iba_2015.pdf

Oliveira JTS, Silva JC. Variação radial da retratibilidade e densidade básica da madeira de Eucalyptus saligna Sm. Revista Árvore 2003; 27(3): 381-385. http://dx.doi. org/10.1590/S0100-67622003000300015.
Oliveira JTS, Tomazello Filho M, Fiedler NC. Avaliação da retratibilidade da madeira de sete espécies de Eucalyptus. Revista Árvore 2010; 34(5): 929-936. http://dx.doi. org/10.1590/S0100-67622010000500018.

Rocha HLS, Paes JB, Miná AJS, Oliveira E. Caracterização físico mecânica da madeira de jurema-preta (Mimosa tenuiflora) visando seu emprego na indústria moveleira. Revista Brasileira de Ciências Agrárias 2015; 10(2): 262267. http://dx.doi.org/10.5039/agraria.v10i2a3772.

Scavanaca L Jr, Garcia, JN. Determinação das propriedades físicas e mecânicas da madeira de Eucalyptus urophylla. Scientia Forestalis 2004; (65): 120-129.

Siau JF. Wood: influence of moisture on physical properties. Virginia: Polytech. Inst. Dep. of Wood Science and Forest Product; 1995. $227 \mathrm{p}$.

Skarr C. Wood-water relations. New York: Springer-Verlag; 1988. 283 p.

Terezo EFM. Reflorestamentos em regiões tropicais. In: Anais do V Congresso Internacional de Compensado e Madeira Tropical [CD-ROM]; 2001; Belém. Belém: ABIMCI/AIMEX/FIEPA; 2001.

Torres PMA, Paes JB, Lira JA Fo, Nascimento JWB. Tratamento preservativo da madeira juvenil de Eucalyptus camaldulensis Dehnh. pelo método de substituição de seiva. Cerne 2011; 17(2): 275-282. http://dx.doi.org/10.1590/ S0104-77602011000200016.

Vital BR. Métodos de determinação da densidade da madeira. Viçosa: Sociedade de Investigações Florestais - SIF; 1984. 21 p. Boletim Técnico, 1.

Watai T. Substituição de espécies de madeiras nativas por madeiras de reflorestamento. In: Anais do VI Congresso Florestal Brasileiro; 1990; Campos do Jordão. São Paulo: SBS/SBEF; 1990. vol. 1, p. 131-133. 